ORIGINAL ARTICLE

\title{
Effects of gastric acid on euro coins: chemical reaction and radiographic appearance after ingestion by infants and children
}

\author{
S Puig, M Scharitzer, K Cengiz, E Jetzinger, L Rupprecht
}

Emerg Med J 2004;21:553-556. doi: 10.1136/emj.2002.004879

See end of article for authors' affiliations

Correspondence to:

Dr S Puig, Department of Radiology, University of Vienna Waehringer

Guertel 18-20, A-1090

Vienna, Austria; stefan.

puig@meduniwien.ac.at

Accepted for publication 19 March 2003 coins of the new European currency $(€)$ corrode when they are Objectives: This study investigated whether coins of the new European currency $(€)$ co
exposed to gastric acid, and whether this change can be detected radiographically.

Methods: The eight different denominations of $€$ coins were immersed for seven days in $0.15 \mathrm{~N}$ hydrochloride acid $(\mathrm{HCl})$, which corresponds to the level of post-prandial gastric acid. A Swedish crown coin and three different Austrian schilling coins were used as controls. The coins were weighed and radiographed daily to evaluate visible corrosions and $\mathrm{HCl}$ was analysed daily for possible dissolved substances.

Results: All coins lost weight within 24 hours after exposure to $\mathrm{HCl}$. The 1, 2, and $5 €$ cent coins developed changes that were visible on radiographs. The weights of all coins decreased by $0.43 \%$ to $11.30 \%$ during one week. The dissolved substances measured in the $\mathrm{HCl}$ corresponded to the different metals and alloys of the coins, except for copper, which does not dissolve in $\mathrm{HCl}$. The highest absolute weight loss was observed in the Swedish crown coin $(0.67 \mathrm{~g})$, and the highest relative weight loss in the 1 Austrian schilling coin (11.30\%). The two $€$ coins that showed the highest absolute and relative weight losses were the $2 €(0.54 \mathrm{~g}$ or $6.35 \%)$ and the $1 €(0.48 \mathrm{~g}$ or $6.39 \%)$ coin.

Conclusions: A higher rate of toxicity for the new European coins compared with coins of other currencies is not expected, unless a massive coin ingestion occurs.
1 ngestion of foreign bodies is a common problem in the paediatric population. Up to $80 \%$ of swallowed foreign bodies are coins. ${ }^{1}$ After passing the oesophagus, these coins are considered to be harmless during their short transit through the gastrointestinal tract. ${ }^{2}$ According to the medical literature, there is no reason for intervention unless the coins do not pass from the stomach within four weeks. ${ }^{3-5}$ Some authors even recommend no treatment at all on the premise that the coin has passed the oesophagus. ${ }^{6}$ However, recently, it has been reported that gastric retention of American zinc based pennies showed corrosions of the coin visible on radiographs after incubation with gastric acid $(\mathrm{HCl})$, and that these coins also decreased in weight. ${ }^{7}$

Since 1 January 2002, about 56 billion coins of the new currency "euro" $(€)$ have been replacing the coins of the national currencies in 12 European countries and even more countries of the European Community (EC) plan to introduce the new currency. ${ }^{8}$

The purpose of our study was to evaluate whether gastric acid has the potential to corrode the $€$ coins and whether the dissolved metals can reach concentrations that make poisoning of children possible. We also investigated whether any radiographic appearance and features of corrosion are visible.

\section{METHODS}

The eight different coins of the new European currency were exposed to postprandial concentrations of gastric acid $(0.15 \mathrm{~N} \mathrm{HCl})$ for seven days. We used only coins minted at the Austrian mint with Austrian symbols on the national side.

The $€$ coins are made of the following metals and alloys: 1 , 2 , and $5 €$ cent coins are made of copper $(\mathrm{Cu})$ covered steel (Fe). The 10, 20, and $50 €$ cent coins are made of an alloy called "Nordic Gold," containing 89\% copper, 5\% aluminium,
$5 \%$ zinc, and $1 \%$ tin. The 1 and $2 €$ coins consist of a bimetal divided into an inner "pill" and an outer "ring" made of nickel-brass and copper-nickel alloys, respectively. The $1 €$ coin has a nickel-brass pill made of $75 \%$ copper and $25 \%$ nickel and a copper-nickel ring consisting of 75\% copper, $20 \%$ zinc, and 5\% nickel (three layers: copper-nickel/nickel/copper nickel). The $2 €$ coin is made with a copper-nickel pill and a nickel-brass ring.

The $€$ coins were tested in three different conditions: new (unused), scratched (simulating "used" coins), and with actively destroyed surfaces. The scratched coins were produced using a drum, where the coins were rotated for one day together with nails. The third group of coins was actively destroyed by scratching the surface with a metal nail (fig l).

A new Swedish 10 crown (SKR) coin made of Nordic Gold, a new Austrian 1 schilling (ATS) made of copper-aluminium alloy, and one 5 and one 10 Austrian schilling coin, both made of a copper-nickel alloy, were used as controls.

All coins were weighed (Sartorius Analytic Scale MClRC210P; Sartorius AG, Göttingen, Germany), photographed, and radiographed before incubation with $\mathrm{HCl}$. Radiological parameters were as follows: $70 \mathrm{kV}$; $10 \mathrm{mAs}$ and $80 \mathrm{kV}$; $11 \mathrm{mAs}$; film-focus distance: $110 \mathrm{~cm}$ with a conventional $x$ ray film system. Two different exposure settings were used because of the different density of coins. The coins were incubated with $0.15 \mathrm{~N} \mathrm{HCl}$ for seven days. For safety reasons, the coins had to stay in the high security laboratory of the mint. These precautions were necessary because the $€$ coins were not available to the public while this study was performed.

The coins were removed daily from the acid, dried, weighed, and brought to the radiology department. $\mathrm{HCl}$ was analysed for dissolved substances using atomic emission spectroscopy with inductive coupled plasma (ISA Jobin Yvon 

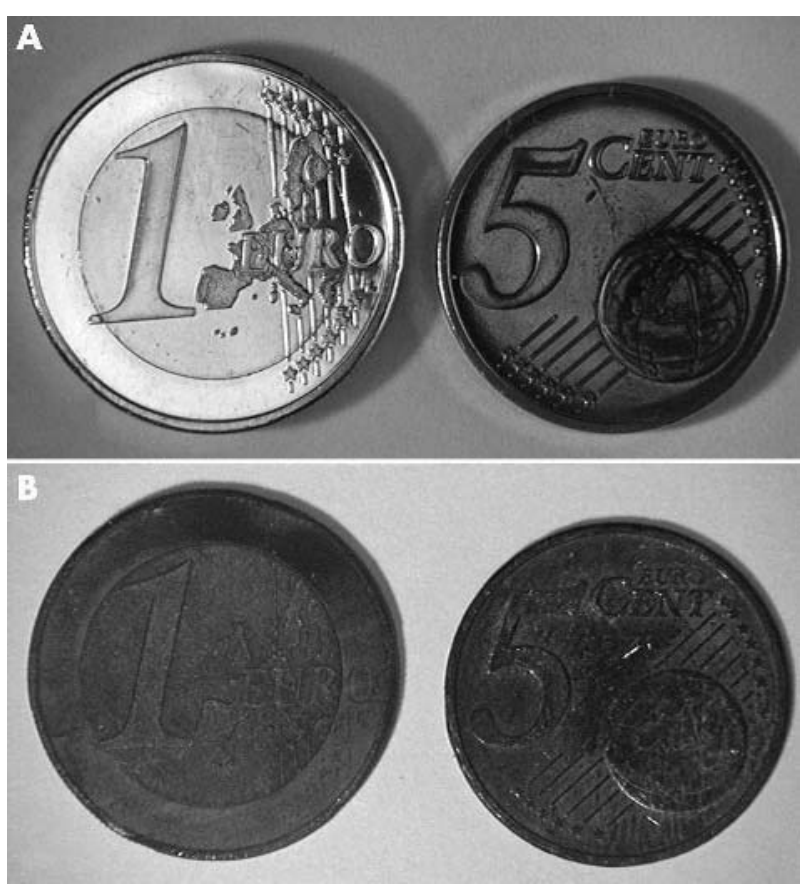

Figure 1 Photograph of the intentionally damaged $1 €$ and the $5 €$ cent coins before (A) and after (B) the investigation. Note the visible changes in the surface of the $€$ coin. The copper cover of the cent coin remained unchanged.

ICP-Spektrometer JY70 PLUS; Instruments SA GmbH, Unteraching, Germany), and the acid was renewed every day. Because of this time consuming procedure, the coins were incubated in the acid only for about 22 hours a day. All coins made of the same material and belonging to the same group (new, scratched, or destroyed surface) were put together in the beaker of the magnetic agitator (Variomag Magnetic Stirrer Multipoint HP; H+P Labortechnik GmbH, Munich, Germany).

Radiological analyses of the films were performed in consensus by two radiologists. The chemical analyses were made by three chemists of the Austrian mint. Each group was blinded to the results of the other one.

\section{RESULTS}

\section{Chemical analysis}

All coins lost weight and the different alloys were found in the acid. The concentrations of the different metals in the acid were similar to the alloys of the coins, except for copper, which does not dissolve in $\mathrm{HCl}$. There was no significant difference between the different groups of coins (new, used, or destroyed). Generally, larger coins lost more weight than smaller ones, but there was no correlation between the surface area and the loss of weight (see tables 1 and 2).

Copper covered steel coins $(0.01,0.02,0.05 €)$

These coins lost between $0.43 \%$ and $5.57 \%$ of their original weight after seven days (table 1). The lowest decrease was shown in the "used" $1 €$ cent coin, and the highest in the "used" $2 €$ cent coin. The $2 €$ coin lost $0.17 \mathrm{~g}$ after seven days' incubation with $\mathrm{HCl}$, which was the highest loss of weight in the $€$ coin group made of copper covered steel. Because copper cannot dissolve in gastric acid, 100\% of weight loss occurred due to dissolved steel (Fe).

Nordic Gold (0.10, $0.20,0.50 €$, and 10 SKR)

The $€$ coins lost between $2.59 \%$ and $6.05 \%$ (table 1 ), and the 10 SKR lost $10.14 \%$ (table 2 ) of their weight. Of the $€$ coins, the used $50 €$ cent coin showed the highest absolute weight loss at $0.47 \mathrm{~g}$. This corresponds to $0.21 \mathrm{~g}$ aluminium, $0.21 \mathrm{~g}$ zinc, and $0.05 \mathrm{~g}$ tin. Of all tested coins, the Swedish crown (10 SKR) lost most weight with $0.67 \mathrm{~g}$.

\section{Nickel alloys $(1.00,2.00 €$ and 5, 10 ATS)}

The $€$ coins lost between $5.79 \%$ and $6.39 \%$ (table 1 ), the 5 ATS coin $7.30 \%$, and the 10 ATS $2.44 \%$ (table 2) of their weight. The highest absolute weight loss was found in the "used" $2 €$ coin, which lost $0.54 \mathrm{~g}$. This corresponds to about $0.20 \mathrm{~g}$ zinc and $0.34 \mathrm{~g}$ nickel. Again, because copper does not dissolve in $\mathrm{HCl}$, only zinc and nickel could be analysed in the liquid.

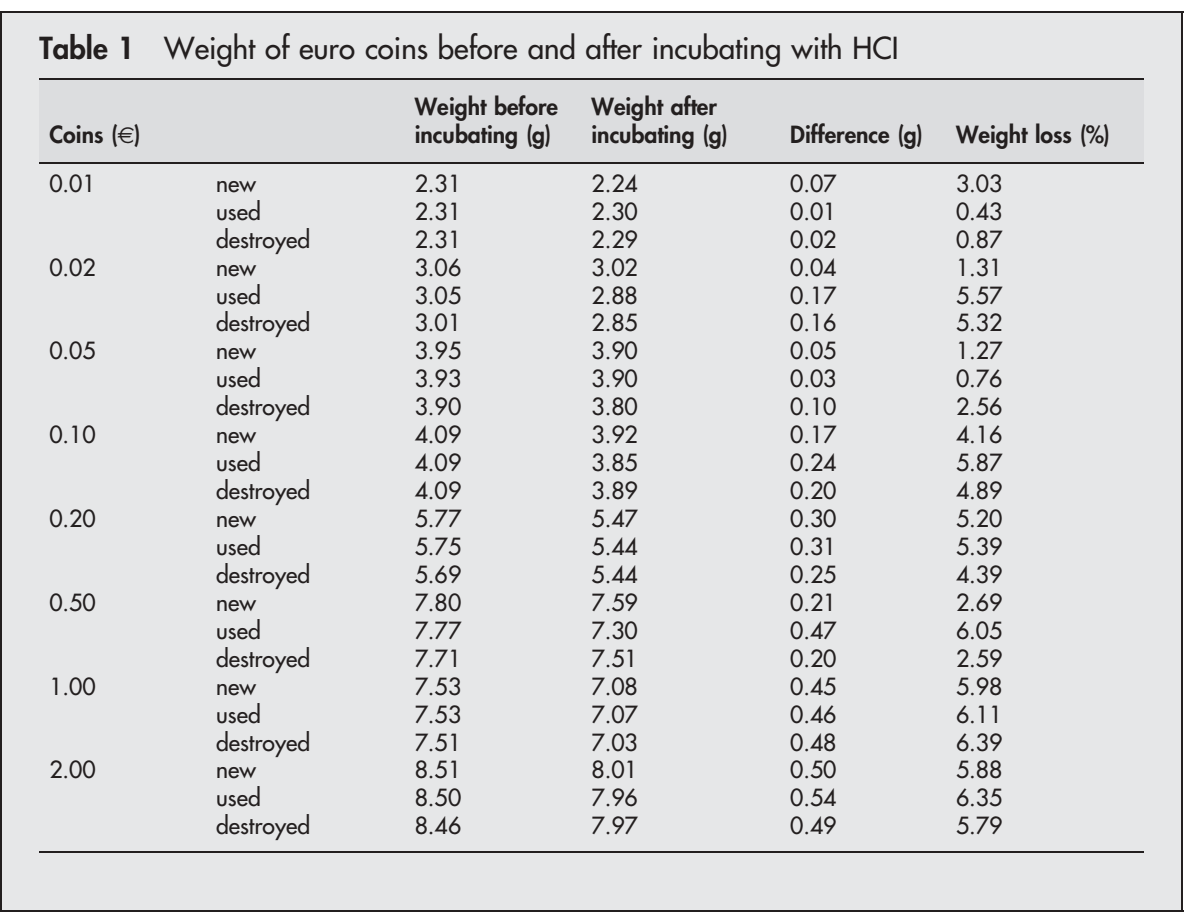




\begin{tabular}{lllll}
\hline Table 2 & \multicolumn{5}{l}{ Weight of control coins before and after incubating with $\mathrm{HCl}$} \\
\hline Control coins & $\begin{array}{l}\text { Weight before } \\
\text { incubating (g) }\end{array}$ & $\begin{array}{l}\text { Weight after } \\
\text { incubating (g) }\end{array}$ & Difference (g) & Weight loss (\%) \\
\hline 1 ATS & 4.16 & 3.69 & 0.47 & 11.30 \\
5 ATS & 4.80 & 4.45 & 0.35 & 7.30 \\
10 ATS & 6.14 & 5.99 & 0.15 & 2.44 \\
10 SKR & 6.61 & 5.94 & 0.67 & 10.14 \\
\hline
\end{tabular}

The 1 ATS coin made of copper-aluminium alloy lost $0.47 \mathrm{~g}$ or $11.30 \%$ or of its weight (table 2 ). This coin showed the highest relative weight loss of all coins.

\section{Radiological analysis}

Coins that lost weight because of a continuously dissolved surface did not show any changes on the radiograph (fig 2). Coins made of copper covered steel, in which the acid dissolved the steel via small defects on the surface of the coins or which were actively destroyed, showed up to $2 \mathrm{~mm}$ large lucencies that increased over time (fig 2). The first lucencies were already visible after one day of incubation. These lucencies may be explained by defects in the copper that occurred during the minting process or by active destruction of the surface. The acid enters through these defects and dissolves the steel inhomogeneously. This inhomogeneous thickness of the steel becomes visible on radiographs. If the acid dissolves the surface homogeneously, no density differences will occur and therefore no lucencies are visible on radiographs.

\section{DISCUSSION}

Coins are the foreign bodies most frequently ingested by children. Ingestion of foreign objects peaks at 10-12 months, when most children crawl and have a strong tendency to put things in their mouth. ${ }^{9}$ Conservative treatment or watchful
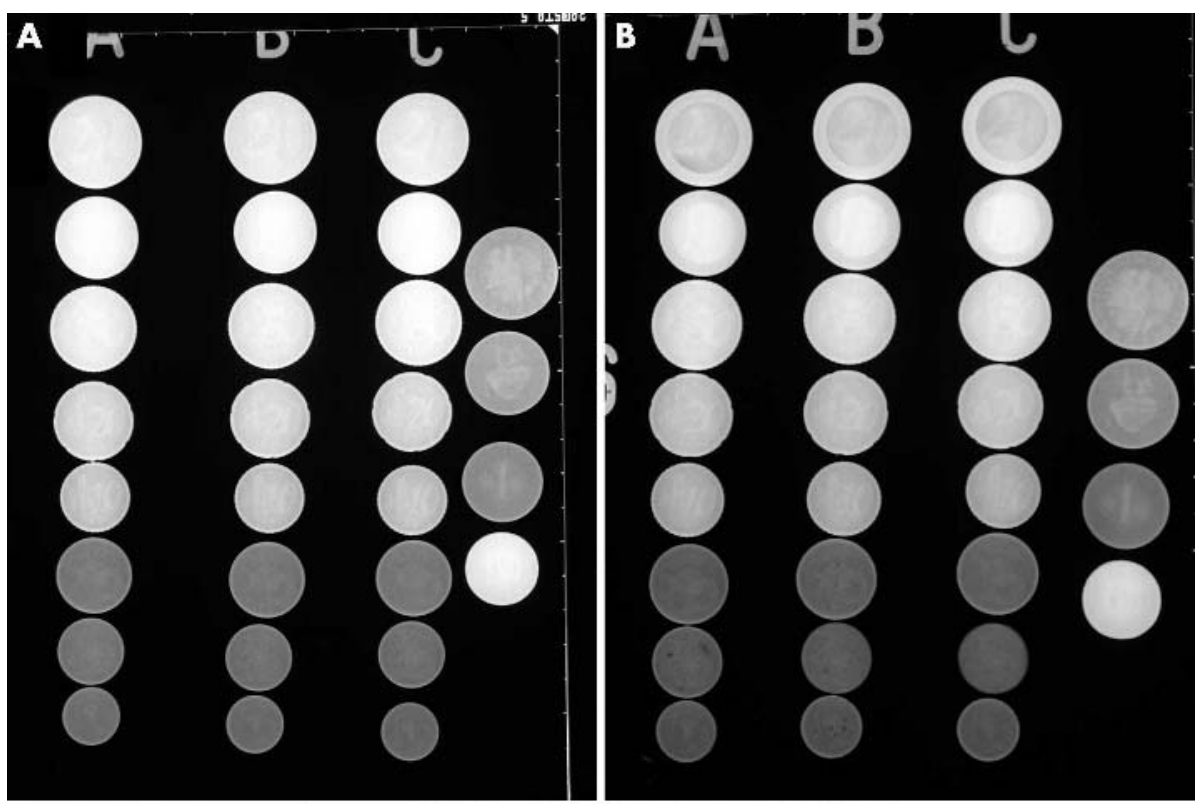

Figure 2 Radiographic appearance of the coins before (A) and after one week's incubation in $\mathrm{HCl}(\mathrm{B})$. Row A shows the "new", row B the "used," and row $C$ the "destroyed" $€$ coins. On the right, the four control coins $(10,5,1$ ATS, 10 SKR) are displayed. Lucencies are only visible on copper covered steel coins - see enlargement of the $5 €$ cent coin (C). The acid may enter through defects in the copper and dissolve the steel only in this location, which leads to irregular thickness of the steel, making it visible on radiographs. In coins where the acid dissolves the surface

homogenously, no defects are visible on the radiographs. (C) An enlargement of a copper covered steel $€$ cent coin after incubation in $\mathrm{HCl}$.

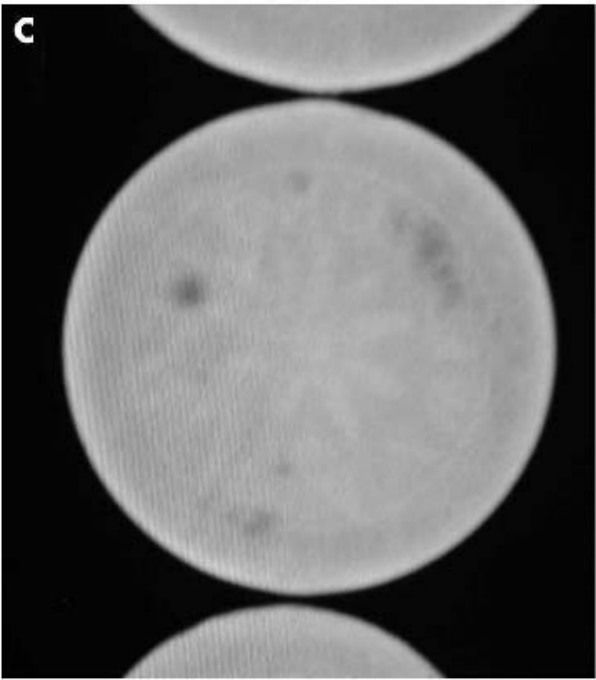


waiting is recommended if the coins have passed the oesophagus. ${ }^{10}$ Some authors suggest waiting up to several weeks if coins have passed into the stomach or even recommend no treatment at all if coins are already in the stomach..$^{3-6}$ This is in contrast with some reports of toxicity after coin ingestion. ${ }^{7112}$ After massive ingestion of zinc based coins, toxicity in humans and in animals living in zoos, have been reported. ${ }^{11}{ }^{13}{ }^{14}$ The toxic effects of zinc absorption include local corrosion and ulceration of the stomach, nausea, vomiting, and abdominal pain. ${ }^{11} 1516$ Systemically, excessive zinc ingestion can also cause anaemia, haemolysis, and derangement of clotting factors, pancreatic dysfunction, pancreatitis, increased amylase activities, copper deficiency, hepatocellular necrosis, acute tubular necrosis, renal failure, and death from multisystem organ failure..$^{11}{ }^{17-20}$

O'Hara et al reported the case of a 2 year old child who presented with vomiting and abdominal pain four days after having swallowed a single zinc based coin. ${ }^{7}$ This coin was a US penny, which is made of a zinc core ( $97.6 \%$ of volume) with a copper coating (2.4\%). ${ }^{21}$ Only the 1 and $2 €$ coins, and the 10,20 , and $50 €$ cent coins, also contain zinc. However, the concentration of zinc is much lower in European than in American coins. The 10, 20, and $50 €$ cent coins contain only $5 \%$ zinc, and the 1 and $2 €$ coins contain about $19 \%$ zinc. The American pennies weigh $2.5 \mathrm{~g}$, have a diameter of $19.05 \mathrm{~mm}$, and a thickness of $1.55 \mathrm{~mm} .{ }^{21}$ These measures are comparable to the 1 and $2 €$ coins, though they have a somewhat larger diameter, and therefore a greater surface. This will support a greater chemical reaction. However, because of the much lower concentration of zinc in the European coins, toxicity is less probable than that reported for the American coins. No reports are available on the toxicity of aluminium after ingestion. There are also no reports of toxicity after swallowing greater amounts of copper, tin, or steel.

We tested the eight $€$ coins in three different conditions ("new", "used", "damaged") because we thought that scratched or damaged coins would show more signs of corrosion. However, no pattern could be identified. This is in accordance with the results of $\mathrm{O}^{\prime}$ Hara et al who did not find a difference in weight loss between damaged and undamaged penny coins in their in vitro experiment. ${ }^{7}$ The $1 €$ and $2 €$ coins were the ones that showed the highest absolute and relative weight loss after one week's exposure to $\mathrm{HCl}$. However, these coins reduced by less than $1 \mathrm{~g}$ or less than $10 \%$ of their original weight.

The radiological evaluation showed that there were visible inhomogenous corrosions along the surface only on a few small $€$ cent coins. This suggests a low possibility of confusing $€$ coins with lead containing foreign bodies or button type batteries after radiological examination..$^{22}$ These are potentially a considerably more dangerous chemical threat than coins are, which has an effect on the further treatment of the patient.

Some authors recommend removing foreign bodies that are more than $2 \mathrm{~cm}$ in diameter, especially when infants and children are concerned. ${ }^{452324}$ The larger weights of these coins may also contribute to the inability of the peristalsis to move them through the gastrointestinal tract. ${ }^{24}$ As five of eight $€$ coins $(0.05,0.20,0.50,1.00$, and $2.00 €)$ are larger than $2 \mathrm{~cm}$ in diameter, it is questionable whether these coins must be removed immediately because it is unlikely that they will pass the pylorus in infants and toddlers.
Our technique had some shortcomings in simulating the physiological conditions in the human stomach: the coins in solution could not be kept at body temperature, and the acid was renewed once a day only. Furthermore, the coins could only be incubated for about 22 hours a day. However, we may conclude that with the new $€$ coins, no higher rate of toxicity is to be expected than that reported to date for other coins. In contrast, the new $€$ coins seem to be safer than the Austrian schilling or the Swedish crown, which we used as controls. Problems may occur because of the comparatively large diameter of certain $€$ coins, which may prevent swallowed coins from leaving the body naturally.

\section{Authors' affiliations}

S Puig, M Scharitzer, Department of Radiology, Medical University of Vienna, Vienna, Austria

K Cengiz, L Rupprecht, Austrian Mint, Vienna, Austria

E Jetzinger, Department of Emergency Medicine, University of Vienna

\section{REFERENCES}

1 Vyas K, Sawant P, Rathi P, et al. Foreign bodies in gut. J Assoc Physicians India 2000;48:394-6.

2 American Society for Gastrointestinal Endoscopy. Guidelines for the management of ingested foreign bodies. Gastrointest Endosc 1995;42:622-5.

3 Blaho KE, Merigian KS, Winbery SL, et al. Foreign body ingestions in the emergency department: case reports and review of treatment. J Emerg Med 1998;16:21-6.

4 Seo JK. Therapeutic endoscopy: removal of gastrointestinal foreign bodies in children. Acta Paediatr Sin 1997;38:183-6.

5 Seo JK. Endoscopic management of gastrointestinal foreign bodies in children. Indian J Pediatr 1999;66(suppl):S75-80.

6 Cheng W, Tam PKH. Foreign-body ingestion in children: experience with 1,265 cases. J Pediatr Surg 1999;34:1472-6.

7 O'Hara SM, Donnelly LF, Chuang E, et al. Gastric retention of zinc-based pennies: radiographic appearance and hazards. Radiology 1999;213:113-17.

8 European Central Bank. The Euro banknotes and coins. Frankfurt am Main, Germany: European Central Bank, 2000.

9 Hiern A, Rinbäck-Weitoft G, Andersson R. Socio-demographic risk factors for home-type injuries in Swedish infants and toddlers. Acta Paediatr 2001;90:61-8.

10 Wunsch R, Zieger B, Darge K, et al. Fremdkörperingestion [Ingestion of foreign bodies] Radiologe 1999;39:472-7.

11 Bennett DR, Baird CJ, Chan KM, et al. Zinc toxicity following massive coin ingestion. Am J Forensic Med Pathol 1997; 18:148-53.

12 Hassan HA, Netchvolodoff C, Raufmann JP. Zinc-induced copper deficiency in a coin swallower. Am J Gastroenterol 2000;95:2975-7.

13 Agnew DW, Barbiers RB, Poppenga RH, et al. Zinc toxicosis in a captive striped hyena (Hyaena hyaena). J Zoo Wildl Med 1999;30:431-4.

14 Murray S, Tell LA, Bush M. Zinc toxicosis in a Celebes ape (Macaca nigra) following ingestion of pennies. J Zoo Wildl Med 1997;28:101-4.

15 Ellenhorn MJ. Ellenhorn's medical toxicology-diagnosis and treatment of human poisoning. 2nd ed. Baltimore: Williams and Wilkins, 1997.

16 McKinney PE, Brent J, Kulig K. Acute zinc chloride ingestion in a child: local and systemic effects. Ann Emerg Med 1994;23:1383-7.

17 Brocks A, Reid H, Glazer G. Acute intravenous zinc poisoning. BMJ 1977;2:1390-1.

18 Broun R, Greist A, Tricot $G$, et al. Excessive zinc ingestion. JAMA 1990;264:1441-3.

19 Hoffman HN, Phyliky RL, Fleming CR. Zinc-induced copper deficiency. Gastroenterology 1988;94:508-12.

20 Meurs KM, Breitschwerdt EB, Baty CJ, et al. Post surgical mortality secondary to zinc toxicity in dogs. Vet Hum Toxicol 1991;33:579-83.

21 The Unites States Mint. Coin specifications. http://www.usmint.gov/ about_the_mint/index.cfm?action = coin_specifications (accessed 26 Dec 2002).

22 Rebhandl W, Steffan I, Schramel P, et al. Release of toxic metals from button batteries retained in the stomach: an in vitro study. J Pediatr Surg 2002;37:87-92.

23 Stack LB, Munter DW. Foreign bodies in the gastrointestinal tract. Emerg Med Clin North Am 1996;14:493-521.

24 Wright KD, Potts DJ. Ingested coins. [Letter]. J Accid Emerg Med 1999;16:239-40 